\title{
Understanding the Callao Cave Depositional History
}

\author{
Armand Salvador Mijares
}

This paper presents a soil micromorphological analysis of the stratigraphic sequence of sediments recorded in the antechamber of Callao Cave, northern Luzon. The study builds on our understanding of the depositional and post-depositional history of the cave sediments and elucidates further our knowledge of human occupation at Callao. The results confirm three in situ periods of human frequentation in the antechamber. The most recent recognisable archaeological horizon dates to ca. $3600 \mathrm{BP}$ and represents a Neolithic occupation layer with ceramics, flake tools, a spindle whorl, faunal remains and human burials. Below this is a layer of volcanic sediment that forms a hiatus in cultural deposition, preceded by a habitation at ca. 25,000 BP characterised by hearths, abundant charcoal and burnt sediments and associated chert flake tools. Below a further ca. $2 \mathrm{~m}$ of almost sterile deposit is the lowest cultural horizon, comprising breccia containing faunal bones and a human metatarsal, dated by uranium series to ca. 67,000 BP. The study demonstrates that Callao Cave was only intermittently and irregularly occupied over the last 70 millennia.

\section{Introduction}

The author has intermittently investigated the Callao Limestone Formation in the Municipality of Peñablanca, Cagayan Province, northern Luzon, since 1999 (Mijares 2001; Figure 7.1). From 2003 onwards, and as part of my PhD supervised by Peter Bellwood, I implemented a more intensive and sustained research program at Callao. The initial project was primarily focused on Neolithic occupation of northern Luzon and comparisons between burial and habitation sites in the Callao karstic formations and the contemporaneous open-air settlement sites of the Cagayan River valley (Mijares 2007). Following the completion of my PhD, I returned to Callao Cave itself to investigate the deeper, older sedimentary sequences that potentially lay undiscovered in the main cave entrance (Mijares et al. 2010).

Callao is the largest cave complex in the Callao karstic formation, with seven chambers and three collapsed roof holes that open to the sky. Since 1979, the antechamber of the cave has been the focus of several periods of archaeological research (Figure 7.2; Cuevas 1980, 1982). My initial excavation at Callao in 2003 focused on the eastern section of the antechamber, close to the eastern cave wall. Deposits were excavated to a depth of $1.3 \mathrm{~m}$ and resulted in the discovery of Palaeolithic and Neolithic activities in the cave (Mijares 2005a). In 2007, inspired by the work of Mike Morwood at Liang Bua, Flores (Morwood and van Ostersee 2007), I went back to Callao 
and excavated my original trenches to a greater depth with the hope of finding evidence of early hominin activity. It was during these excavations that we were able to recover a human third metatarsal, dated by Uranium Series to $c a$. $67,000 \mathrm{BP}$, and recognised as potentially one of the oldest Homo sapiens bones discovered in Southeast Asia (Mijares et al. 2010; Heaney et al. 2011).

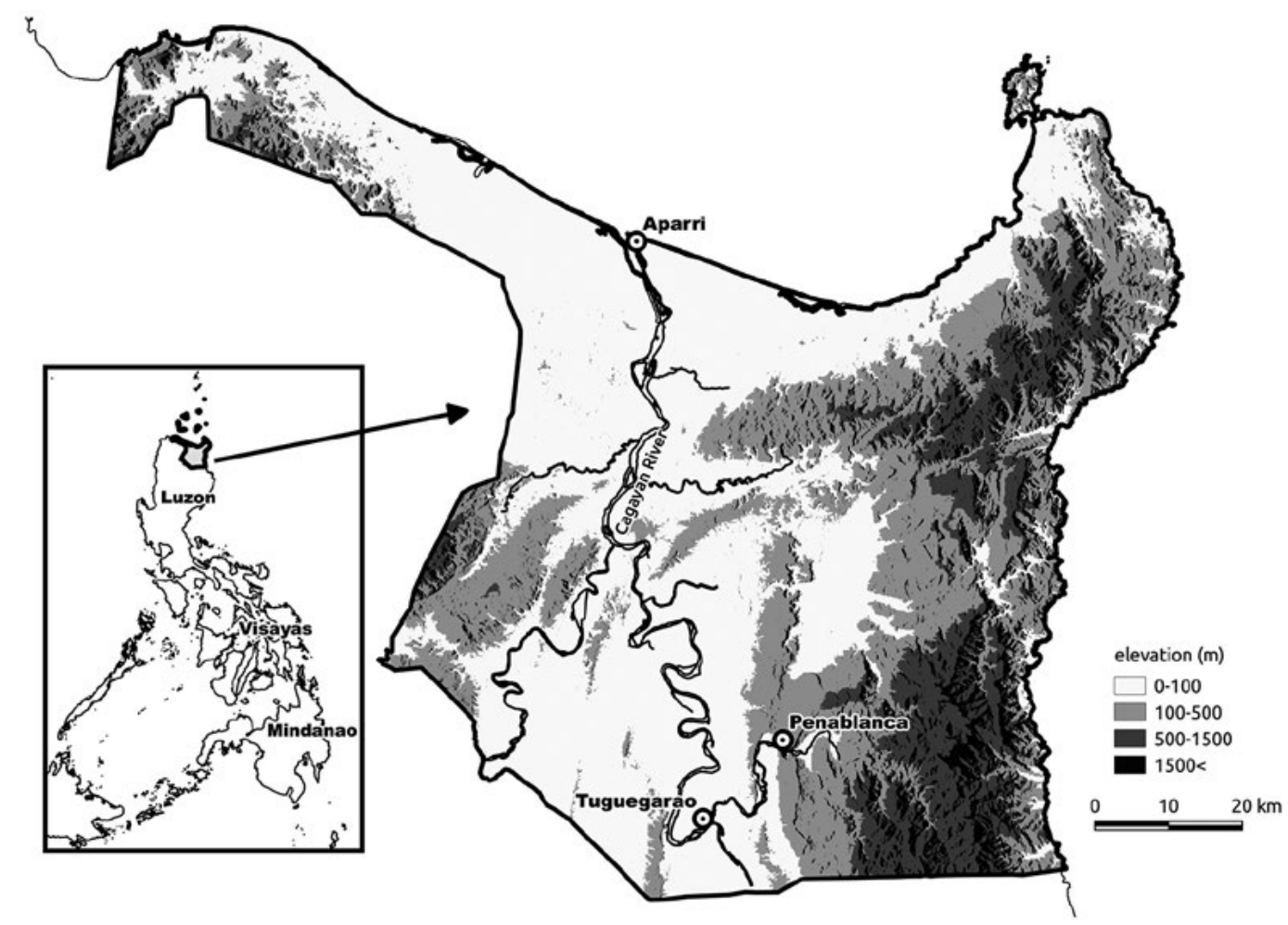

Figure 7.1 The location of Peñablanca karst formations in northern Luzon, Philippines.

Source: E. Robles and A. Mijares.

Since 1979, a total of eight trenches have been excavated within the Callao antechamber and one of the outstanding issues has been correlation of the sedimentary and stratigraphic sequences across the cave entrance. As Anderson (1997: 614) has noted with respect to Lang Rongrien cave in southern Thailand, a particularly difficult problem is correlating occupational debris from one part of a cave with deposits and materials from another part, without physically connecting stratigraphic units by a single excavated profile. In this paper, soil micromorphology, corroborated by macroscopic observations, phytolith analysis, SEM-EDXA analysis and $\mathrm{pH}$ testing are used to correlate the layers within the different excavation units in the antechamber of Callao Cave. The data presented here are from excavations carried out in 2003, 2007 and 2009, plus a re-excavation of one unfinished square from the 1979-1980 excavation seasons. Linking the stratigraphic sequences across the cave entrance has provided insights into the depositional histories of accumulating sediments and correlation of human activity throughout the antechamber. 


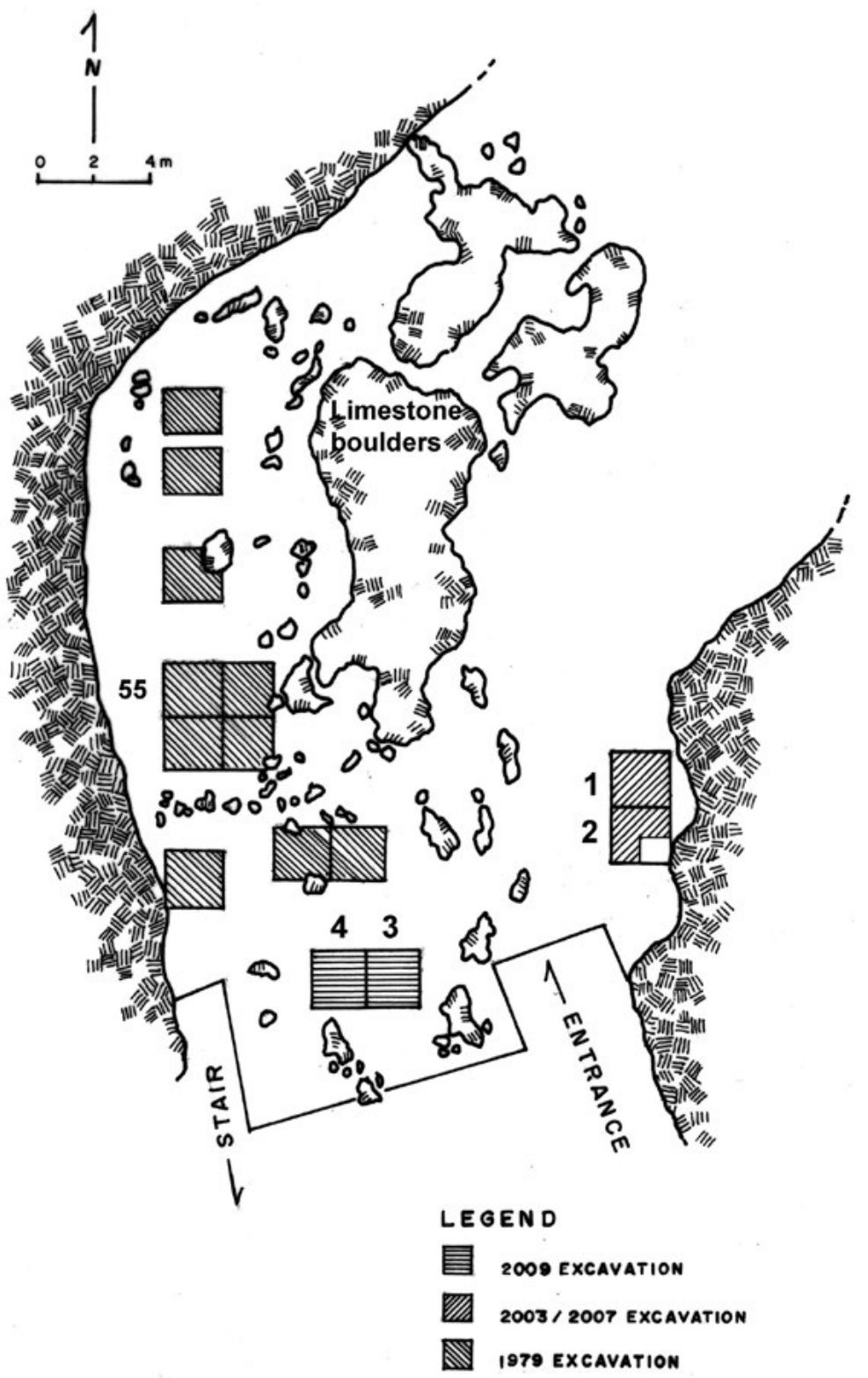

Figure 7.2 The locations of the Callao Cave excavation units.

Source: A. Mijares.

\section{Archaeological background}

A team from the National Museum of the Philippines led by M. Cuevas first excavated Callao Cave in 1979-1980. The archaeologists excavated a $4 \mathrm{~m}^{2}$ trench (containing squares numbered 45, 46, 55 and 56) to a depth of 1.9 m below modern ground surface (bms; Cuevas 1980). In 1980-1982, research continued with the excavation of squares 17, 25, 27, 28, 73, 96 and 108, to an average depth of $2 \mathrm{~m}$ bms (Cuevas 1982). In 2003, Mijares (2005a) excavated an 8 x $4 \mathrm{~m}$ trench near the eastern wall of the antechamber by the cave entrance. This was divided into two $4 \mathrm{~m}^{2}$ squares, termed squares 1 and 2 (Figure 7.2), and excavated to a depth of $1.3 \mathrm{~m}$ below the surface. In 2007, the same trench was excavated further, to bedrock, at $3.8 \mathrm{~m}$. The trench yielded 11 soil micromorphology samples (Figure 7.3), of which five were collected from the northern wall of the excavation trench in 2003, and the remaining six from the eastern wall in 2007. 
In 2009, part of the 1979-1980 square 55 was further excavated to $7.5 \mathrm{~m}$ depth in a $1 \mathrm{~m}^{2}$ trench in the northwest corner. The original stratigraphic description of Square 55 was checked and forms the basis for comparison with the results of the 2003 and 2007 excavations. Also in 2009, another $8 \times 4 \mathrm{~m}$ trench (Squares 3 and 4 ) was excavated towards the cave entrance, near a large boulder located under the drip-line. This trench reached a maximum depth of $4 \mathrm{~m}$ bms.

To understand the depositional history of the Callao antechamber the stratigraphic profiles in sample squares 55,1/2, and 3/4 were studied and correlated.

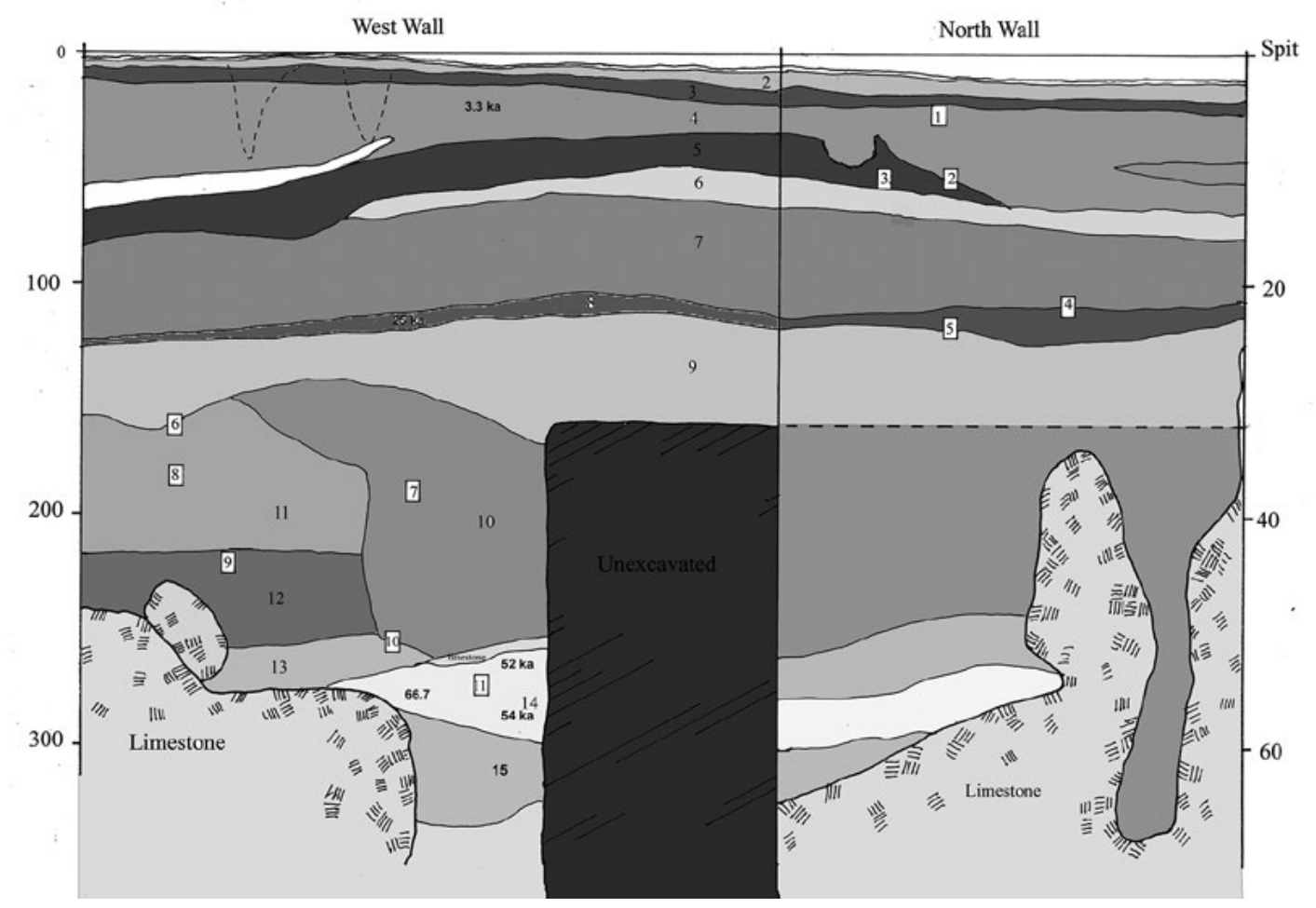

Figure 7.3 Sections of the west and north walls of Squares 1 and 2 showing the locations of the micromorphological soil samples (white boxes).

Source: A. Mijares.

\section{Soil micromorphology}

Soil micromorphology, the study of undisturbed soil and sediment samples in thin section, is often used to conduct fine-grained analysis of site formation processes (e.g. Courty et al. 1989). In Southeast Asia, its application to archaeological sites has steadily increased in recent years. It was first applied in Malaysia, particularly in the Tingkayu site complex in Sabah (Magee 1988), at Gua Gunung Runtuh (Zauyah 1994) in the Malay Peninsula and more recently in Niah Cave, Sarawak (Lewis 2003, 2004; Stephens et al. 2005). In the Philippines, soil micromorphology has been employed at Tabon and Ille Caves on Palawan (Lewis 2004, 2007), and in Eme and Dalan Serkot Caves in the Cagayan Valley of northern Luzon (Mijares and Lewis 2009). The approach has also been applied to an alluvial deposit sealed beneath a shell midden at the site of Nagsabaran, also in the Cagayan Valley (Mijares 2005b).

Samples for this study were recovered from standing profiles and taken as blocks in tins driven into the sections. The samples were air dried, then impregnated with crystic resin and hardened to form solid blocks from which 'slices' (thin sections) were cut $(4 \times 6 \times 0.8 \mathrm{~cm})$. The samples 
were then mounted on glass slides and ground to produce $25 \mu \mathrm{m}$ thin sections, which were observed under plane and crossed polar light at 40 and $100 \mathrm{X}$ magnifications (Tables 7.1 and 7.2). The following bibliographic resources were consulted to describe the observed features: Adams and Mackenzie 2001, Adams et al. 1984, Bullock et al. 1985, Courty et al. 1989, Fitzpatrick 1984, Mackenzie and Adams 1994, Stoops 2003.

\section{Results}

\section{Stratigraphic description}

The cave deposits at Callao are generally undulating, varying in depth within and between excavation trenches. Excavation of the sedimentary sequences generally proceeded by removing layers in $5 \mathrm{~cm}$ spits and following the natural contours of different deposits (where possible). All the excavation trenches at Callao produced a relatively similar sequence of upper deposits to a depth of $1.5 \mathrm{~m}$, albeit with sediments of varying thickness across the antechamber.

Layer 1 (Spit 1) was a thin, loose surface deposit containing modern materials. Layer 2 (Spit 2) is more compact and contains Chinese glass beads, earthenware sherds, bones and lithic debris.

Layer 3 (Spits 3-4), was a yellowish-red clay sediment of late Neolithic date (ca. 3000 BP) containing shell beads, clay lingling-o earrings, brown, red-slipped and black earthenware sherds, flake tools, human bones and teeth, bat bones, riverine and land snail shells, and a single spindle whorl recovered during the 1980 excavations (Cuevas 1980). In addition, 38 tubular shell beads were recovered, measuring 3 to $6 \mathrm{~mm}$ in length and 1 to $4 \mathrm{~mm}$ in diameter. The perforations seem to have been drilled from both sides using a lithic implement that produced the typical hourglass shape, with diameters ranging from 1.5 to $2.5 \mathrm{~mm}$. Disarticulated and fragmentary human bones suggest disturbance that might have occurred during prehistoric times. Within this level a calcium carbonate cemented deposit occurred in the west central part of two squares, making excavation and recovery difficult (Mijares 2005a).

Layer 4 (Spits 5-8) was also a yellowish-red clay deposit that still contained earthenware pottery with brown, red-slipped and black surface finishes, but this layer yielded no lingling-o earrings or shell beads. A red-slipped carinated sherd, with double parallel incisions enclosing a triangle with punctate in-filling similar in shape, decoration and form to the earthenware from the ca. 3500-3000 BP Magapit Hill site near the main Cagayan River (Aoyagi et al. 1993), was recovered (Mijares 2005a). Human bones, stone flakes, riverine and terrestrial gastropod shells were collected. Four deer teeth, a wild boar tusk and nine other pig teeth were also found. One AMS radiocarbon determination on charcoal dates this layer to $3335 \pm 34$ uncal. BP (Wk-17010) or 3693-3527 cal. BP (using Oxcal 4.2 Intcal.13; Bronk Ramsey et al. 2010). Layer $4 \mathrm{~b}$ was a distinctive reddish and loose sandy silt loam that forms an intermediary layer in the northeast corner of Square 1 (Mijares 2005a).

Layer 5 (Spits 8-10) was a black sandy deposit devoid of cultural remains. Though no artefacts were recovered, phytolith identification showed grass to be dominant in this layer, accounting for 53 per cent of the microfossils recorded. Other phytoliths identified were palm (Arecaceae), bamboo and sedge (Cyperaceae) (Mijares 2007).

Layers 6 (Spits 10-13) and 7 (Spits 14-20) were geogenic deposits devoid of cultural materials. Both contain inter-bedded layers of cemented as well as extremely loose sand. Layer 7 had a reddish hue suggesting that it had undergone oxidation. An Energy Dispersive X-ray Analysis (EDXA) on impregnated sediment from this layer was conducted using a Jeol 6400 SEM. 
The EDXA result shows that the grains are high in silica ( $\mathrm{Si}$ ) and aluminium (Al), suggesting that the deposit derives from volcanic ash. Minerals identified include plagioclase, quartz, ilmenite and possible garnet (almandine) (Mijares 2007).

In Layer 8 (Spit 21), chert flake tools were recovered. A probable hearth was also observed at the south end of Square 1 and fragmentary burnt cervid bones were recovered. An AMS radiocarbon determination on charcoal collected from an in situ hearth from this layer is $25,968 \pm 373$ uncal. BP (Wk-14881) or 28,980-27,420 cal. BP (using Oxcal 4.2 Intcal.13; Bronk Ramsey et al. 2010). The silt loam Layer 9 (Spits 26-32) was devoid of cultural remains apart from a few sparsely distributed burnt bones.

In 2007 the team reduced the size of the 2003 excavation trench at a depth of $160 \mathrm{~cm}$ below surface and only excavated the adjacent southern end of Square 1 and northern end of Square 2. There were two distinct sedimentary deposits in the excavation area. The yellowish-brown clay at the north end designated Layer 10 (Spits 31-50) was devoid of cultural materials. At the southern end, an olive-brown clay designated Layer 11 (Spits 31 to 43), produced a flake tool, a chert core and faunal remains, mostly deer. Layer 10 is stratigraphically younger than Layer 11 and seems to be the infilling of a gully that was eroded and truncated during the deposition of Layer 9. Layer 12 (Spits 44-50) was a silty clay loam containing several large bones including a deer scapula, the proximal end of a humerus, and a broken antler (Piper and Mijares 2007).

In Spits 51-53 of the clay Layer 13 the bones and teeth of deer were widespread. In Spit 54 ( $270 \mathrm{~cm}$ below the surface), the team encountered a cemented carbonate-rich breccia (Layer 14; Spits 54-59). This produced 533 faunal bone fragments, mostly deer, pig and bovine (Piper and Mijares 2007). A number of small mammal fossils were also recovered and identified as murid rodents belonging to the genera Batomys and Apomys (Heaney et al. 2011). It was also within this layer that the hominin third metatarsal (MT3) was recovered. The dating of two cervid teeth and the hominin MT3 by U-series ablation produced minimum ages of 52,000, 54,000 and 66,700 BP respectively, from depths between 275 and $295 \mathrm{~cm}$ (Mijares et al. 2010).

Layer 15 (Spits 60-68) below Layer 14 consisted of interbedded, loose and cemented sediment. One cervid antler fragment was recovered from this layer at a depth of $345 \mathrm{~cm}$. Below this was bedrock.

\section{Description of the soil micromorphology samples}

The qualitative and semi-quantitative descriptions of the samples are summarised in Tables 1 and 2. The following are the specific descriptions of each sample. Callao 1 (Figure 7.4, no. 1) was taken from the upper boundary of Layer 4, underlying Layer 3, and is characterised by an assemblage of earthenware pottery, human skeletal remains and a few flake tools. The sample shows heavily bioturbated sediments, with frequent channels and circular poroids made by faunal activity, and a crumb microstructure. Clay coatings were seen on void walls and grains, as well as in aggregates, and micrite impregnates the groundmass, as well as coating some bone fragments. A zone of depletion in the mid-section of the slide shows the loss of iron-rich minerals, probably due to water or faunal activity. Anthropogenic deposits observed in the thin section included small fragments of earthenware, abundant charcoal and charred plant residue, mostly wood. 

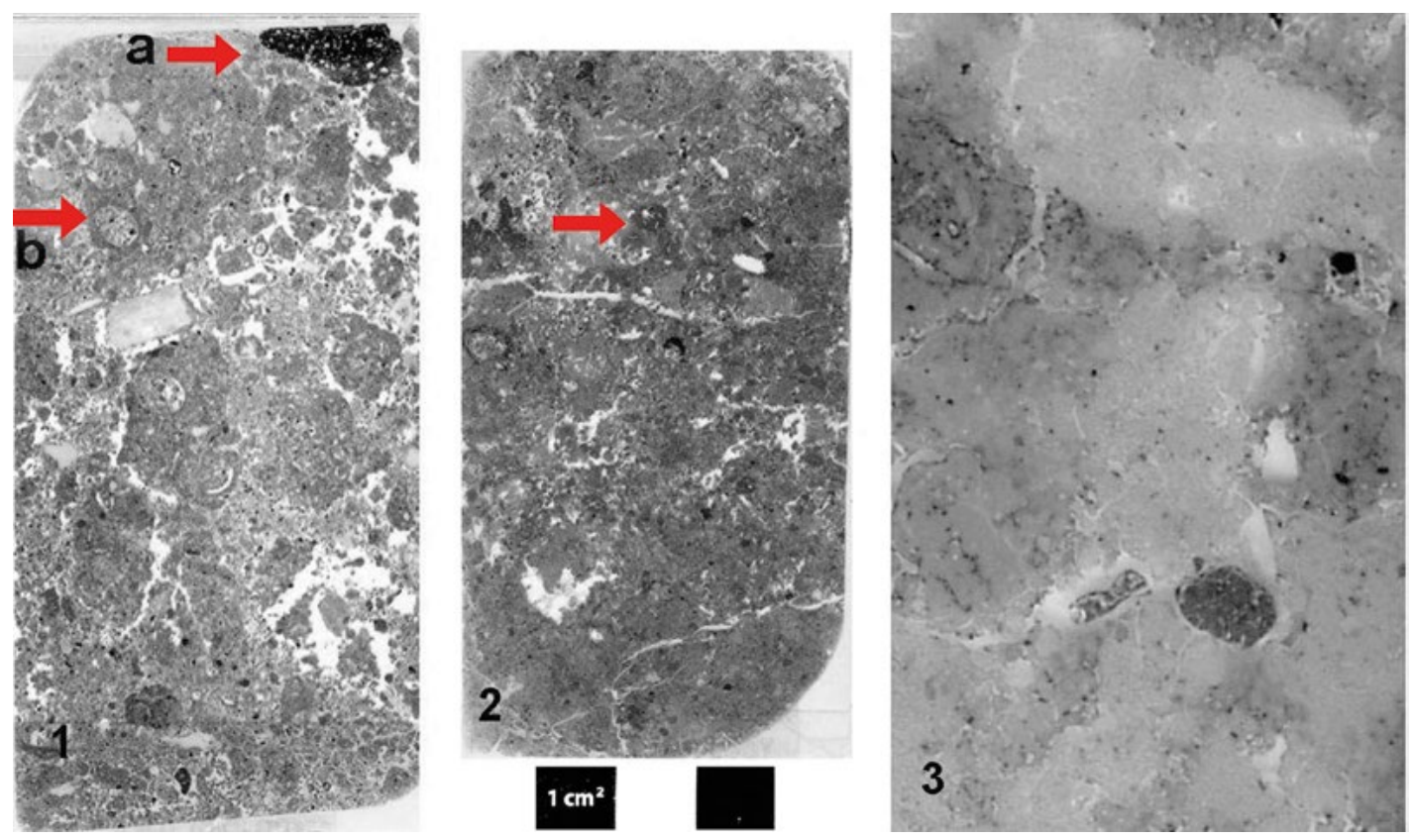

Figure 7.4 Sample thin sections from Callao Cave.

1. Sample 1, with arrow 'a' showing a fragment of a pot, and arrow ' $b$ ' showing faunal activity.

2. Sample 4, with arrow showing fragments of burnt sediment in the 26 ka layer.

3. Sample 11, from the $67 \mathrm{ka}$ breccia layer.

scale bar $1 \mathrm{~cm}$.

Source: A. Mijares.

Callao 2 was taken from the lower boundary of Layer 4 (over Layer 5). Localised burning produced abundant charcoal and had oxidised the sediment, turning it a reddish colour; these features are probably related to a hearth event. Deposition of leached clay was observed in the coatings on grains, aggregates and bones. Precipitation of calcium carbonate was also observed, with the pseudomorphising and coating of bones with micrite and sparite.

Callao 3 was taken from Layer 5 . While the layer was devoid of cultural materials, the thin section did contain burnt organic material (Figure 7.5B), probably of grass and sedge, and phytoliths.
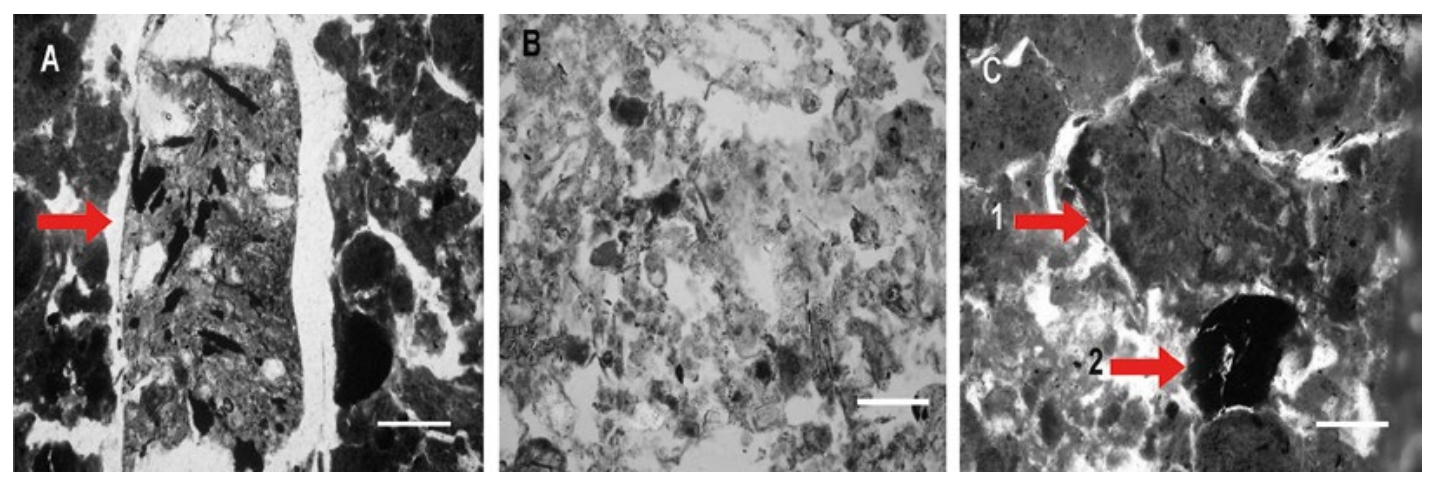

Figure 7.5 Sample thin sections from Callao Cave.

A. Arrow showing faunal excrement (Sample 4).

B. Biological remains in Layer 5 (Sample 3).

C. Arrow 1 showing a rubified ped and arrow 2 showing charcoal (Sample 5).

Scale bar $200 \mu \mathrm{m}$.

Source: A. Mijares. 
Callao 4 and 5 were taken from Layer 8 (Figure 7.4, no. 2). In thin section that deposit has a mixed blocky and crumb structure, with evidence of bioturbation that is also observed in the large horizontal channels partially infilled with faunal excrement (Figure 7.5A). Remains of roots were also observed (Figure 7.5B). The layer was evidently subjected to wetting and drying events, as characterised by its blocky structure, granostriated fabric and high iron nodule content. Precipitation of calcium carbonate in the form of micritic coatings and infilling of voids is evident. During excavation a probable hearth was observed in this layer, which contained oxidised reddish sediment and charcoal (Figure 7.5C). The thin section also showed burning features including charcoal, other burnt plant residues and possible ash aggregates. A dark reddish-brown fabric pedofeature observed in the thin section could be oxidised sediment related to the hearth event.

Callao 11 was taken from Layer 14 (Figure 7.4, no. 3). The sample was highly impregnated with micrite, particularly in the central area. The sediment has angular blocky structure with moderately developed pedality. The observed voids consisted of planes with partially accommodated walls and vughs (small rock or vein cavities).

Callao 6 was taken between Layers 9 and 11. The upper portion (Layer 9) contains many inclusions of limestone measuring 10 to $20 \mathrm{~mm}$. The lower portion (Layer 11) has a silty clay matrix. This sediment has a sub-angular structure with moderately developed pedality. Coatings of peds and void walls with clay and sparite infillings of pores were recorded. Reddish-orange rounded nodules, which appear to be of 'dirty' clay, were also observed. Callao 7 was taken from Layer 10 and is massive, but can be divided into two by a break near the mid-section. The walls of the break are accommodating, which might signify that it is recent. The sediment consists of a silty-clay with angular blocky structure and weak pedality. The only organic matter observed was charcoal fragments with a size range of $50-300 \mu \mathrm{m}$, and 2 per cent frequency. No bone or shell was observed. Orange-red limpid clay was recorded in rounded aggregates with a size range of 50-200 $\mu \mathrm{m}$. There were also sub-angular, strongly impregnated typic nodules. Excrements of rounded to oblong shape and $500 \mu \mathrm{m}$ in size were seen filling channels.

Callao 8 was taken in the middle of the massive Layer 11. The lower part contained gravel size sub-angular limestone bioclasts (molluscs) (Figure 7.6A). This sample has a sub-angular blocky structure with moderately developed pedality. Sparite crystals were observed infilling voids and coating channel walls. Oblong-shaped excrements $600 \mu \mathrm{m}$ in diameter were also observed in channels.
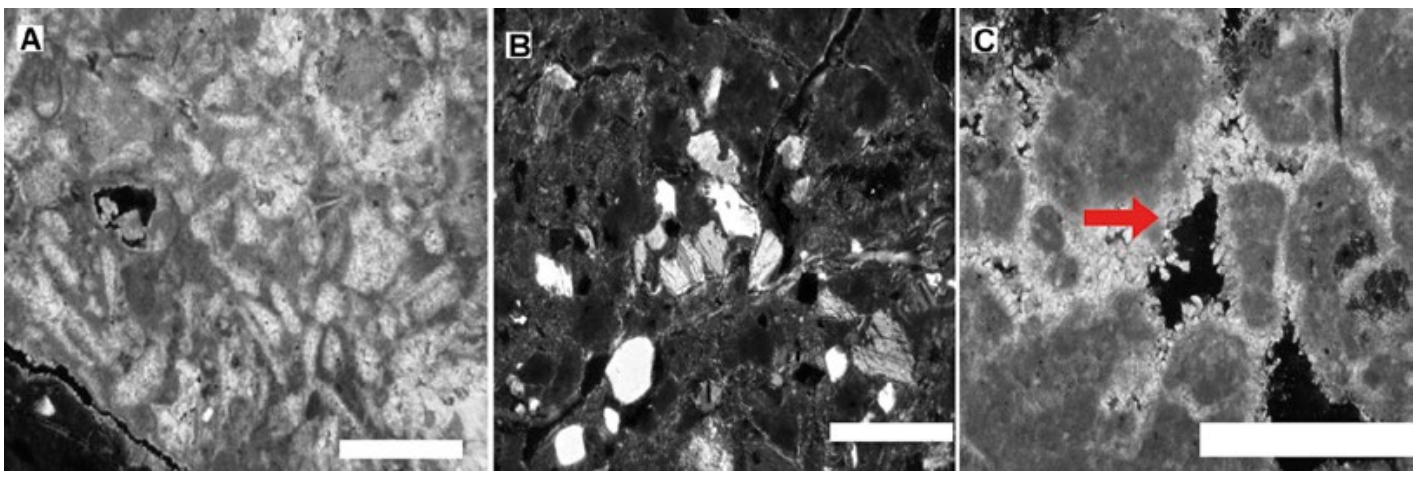

Figure 7.6 Sample thin sections from Callao Cave.

A. Limestone fragment with bioclast (mollusc) inclusions (Sample 8).

B. Volcanic minerals in a clay matrix (Sample 9).

C. Arrow pointing to equant calcite of meteoric phreatic origin (Sample 11).

scale bar $1000 \mu \mathrm{m}$.

Source: A. Mijares.

\section{terra australis 45}




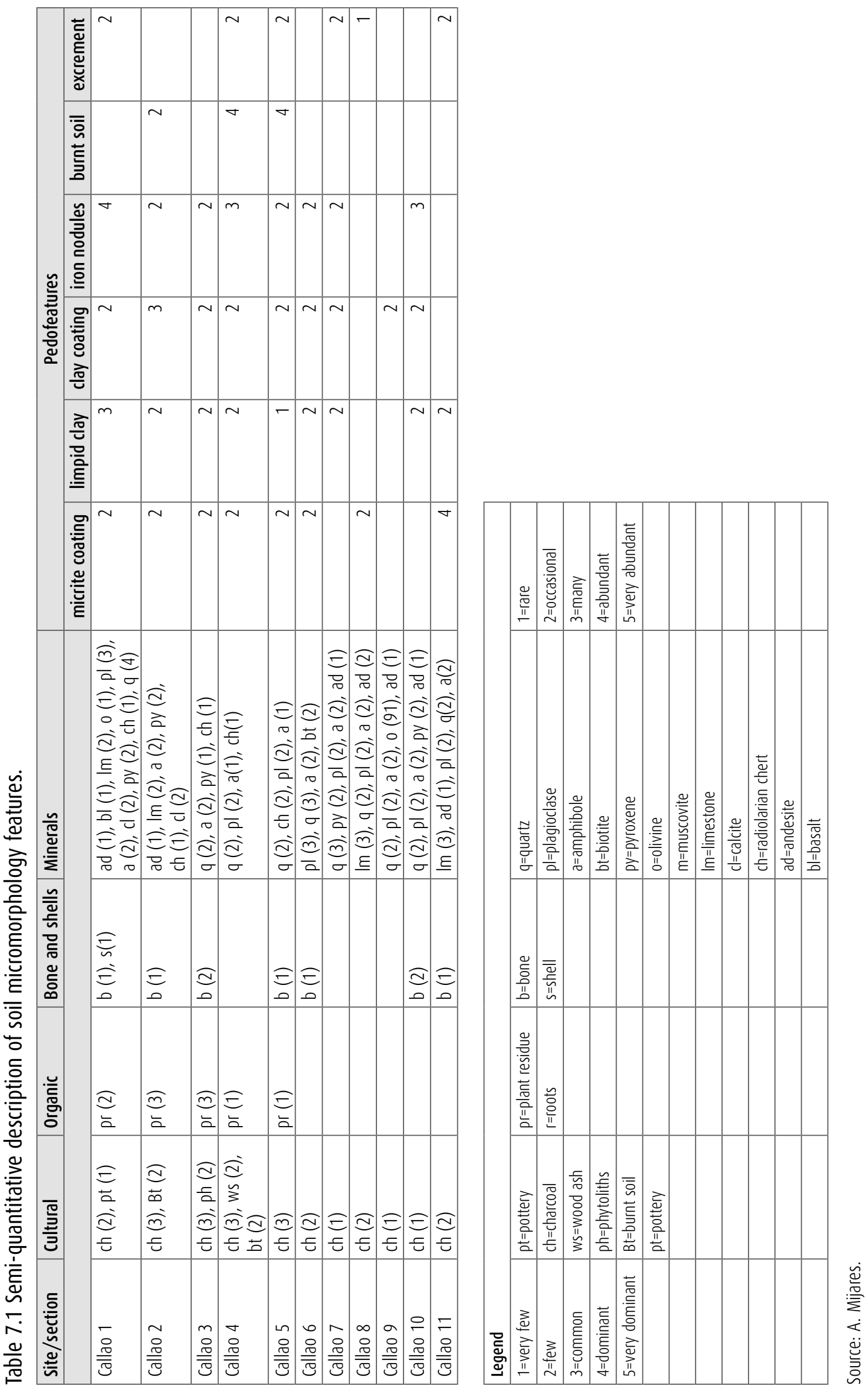



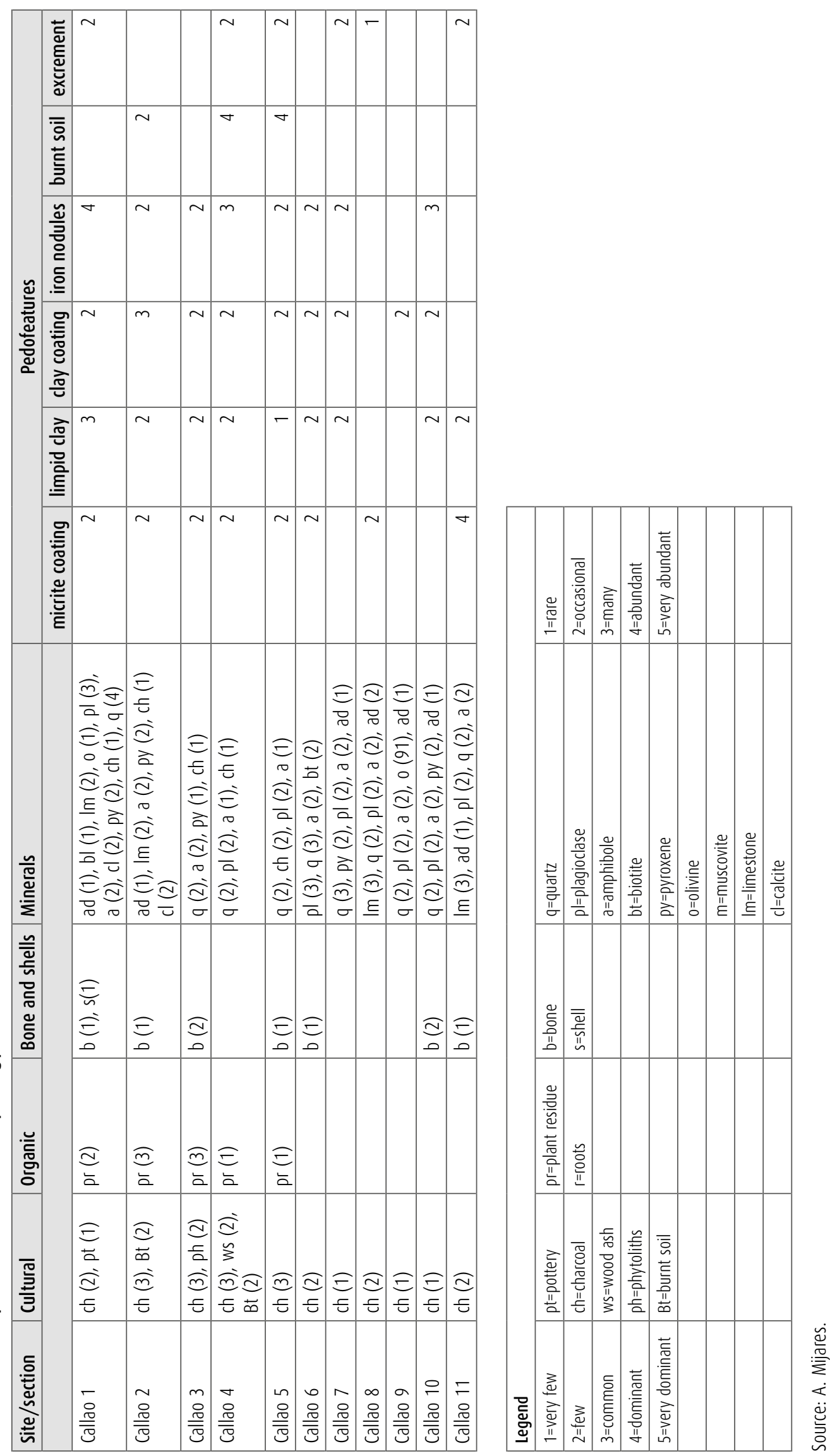
Callao 9 was taken just below the border of Layer 11, within Layer 12 (Figure 7.6B). The layer is a massive deposit macroscopically, with large channels. The thin section sample has a sub-angular blocky structure with moderate pedality and a silty clay loam texture. Hypo-coating of channel walls was observed.

Callao 10 was taken from a massive deposit between Layers 10 and 13. It has a large ( $3 \mathrm{~mm}$ wide) channel at the mid-section that divides the sample; this could be a recent break. The sediment has subangular blocky structure with moderate pedality. The groundmass, which has a silty clay loam texture, is poorly sorted. Dark reddish nodules of fine matrix were observed as well as limpid clay aggregates. Clay coatings were also identified.

The matrix of Callao 11 Layer 14 was moderately sorted with a silty clay loam texture, and is cemented with equant calcite of meteoric phreatic origin (Figure 7.6C). Limestone fragments between $250 \mu \mathrm{m}$ to $8 \mathrm{~mm}$ in size are the dominant mineral inclusions. Volcanic rock fragments and minerals are also present. This deposit also contained rounded yellow orange aggregates $(125-250 \mu \mathrm{m})$ of possible limpid clay and excrements of ellipsoid and cylinder shapes containing organic minerals $(1,500-2,500 \mu \mathrm{m})$.

\section{Discussion}

The following interpretation of depositional history in the Callao antechamber begins from the lowest known layer upwards, and emphasis is placed on those archaeological layers with evidence of human activity (Table 7.3, Figure 7.7).

Table 7.3 Stratigraphic correlation between Squares 1 and 2, 3 and 4, and 55 .

\begin{tabular}{|l|l|l|l|}
\hline Square $\mathbf{1 / 2}$ & Square $\mathbf{3 / 4}$ & Square 55 & Descriptions \\
\hline L1 & L1 & & Modern debris \\
\hline L3/L4 & L2 & L1/L2 & 3.3 ka (Neolithic) \\
\hline L5 & missing & L3 & Organic layer \\
\hline missing & L3 & L4/L5 & Sterile layer \\
\hline L6 & L4 & L7/L8 & volcanic \\
\hline L7 & missing & L9 & Sterile layer \\
\hline L8 & missing & L10 & 25 ka occupation layer \\
\hline L9-13 & L5 & L11-16 & Few animal bones \\
\hline L14 & L6 & L17 & 66.7 ka, human and animal bones \\
\hline
\end{tabular}

Note: Correlation is based on field observation, texture and colour of the sediments. Missing layers could be due to erosion or the material was not deposited such as organic materials (Layer 5).

Source: A. Mijares. 


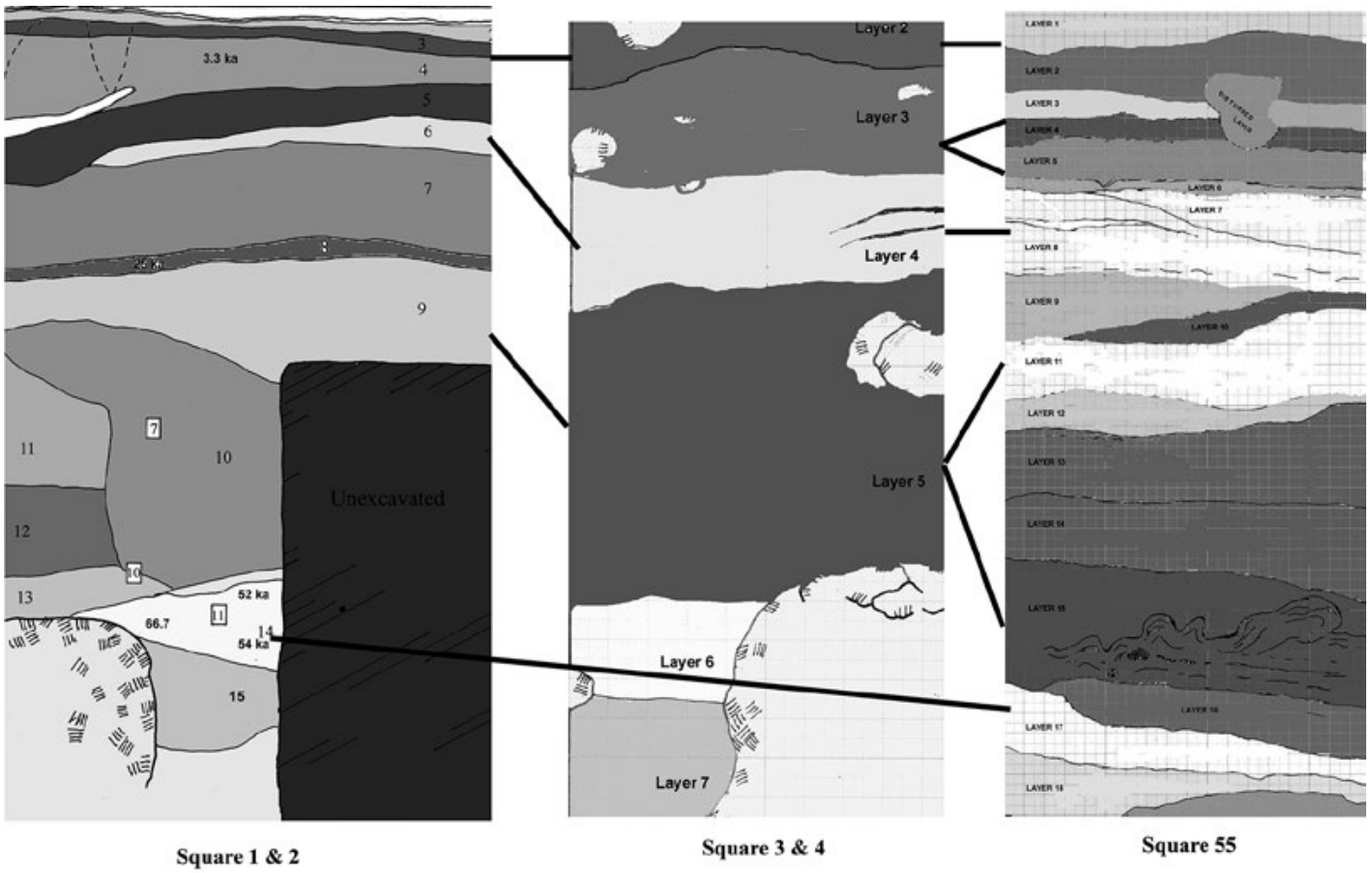

Figure 7.7 Stratigraphic correlations between Squares 1 and 2, 3 and 4, and 55.

Source: A. Mijares.

The 1979-1980 excavations of Square 55 reached a depth of $c a .7 .5 \mathrm{~m}$ below surface (BS) before exposing what the excavator deemed to be bedrock (Cuevas 1980). Cuevas (1980) identified a total of six layers in the sedimentary sequence, with the lowest archaeological layer recorded at $3.5 \mathrm{~m}$ below ground surface. During re-excavation and re-analysis of Square 55 in 2009, a total of 27 layers were identified.

The stratigraphic sequence in the upper $4 \mathrm{~m}$ of 1979-1980 Square 55 can be correlated with Squares 1-2 and 3-4 from the more recent excavations, though not all the layers were observed in all units (Figure 7.7; Table 7.3). The lower layers of Square 55 stand alone as representing the lowest deposits of the antechamber excavated. Unfortunately, neither micromorphological nor biological samples were collected from the lowest levels of Square 55 and their composition cannot be assessed. But from Layer 19 ( $c a .4 \mathrm{~m} \mathrm{BS}$ ) to Layer 27 at $7.3 \mathrm{~m} \mathrm{BS}$ the sediments are clays with colours ranging from dark yellowish-brown to yellowish-brown. Layer 21 at $4.65 \mathrm{~m}$ BS is the lowest volcanic ash deposit found in the cave. No evidence of hominin activity was recorded in any of these lower deposits.

Layer 14 in Square 1-2, there is a hominin and other bone-bearing breccia that can be correlated with Layer 6 in Squares 3-4 and Layer 17 in Square 55 (Figure 7.7). The sediment is a silty clay loam with microscopic charcoal fragments $(50-1,000 \mu \mathrm{m})$ that might be associated with human activity. The breccia results from impregnation of the matrix with micrite. The identification of equant calcite of meteoric phreatic origin could mean that some of the sediments were deposited in a phreatic (hydrological) environment and subsequently reworked when exposed to subaerial conditions and secondary movement (Adams and Mackenzie 2001). The faunal bones have surface polishing and rounding that could have been caused by erosion and water transport (Mijares et al. 2010). The lower layers in Square 55 could also have been deposited initially in a phreatic environment. The spatial distribution of the faunal bone within this deposit shows linear 
concentrations extending from the entrance of the cave towards the interior. This implies water transport and post-depositional redistribution of vertebrate remains from the entrance towards the interior within a possible low energy flow channel.

The deposits in Layers 9-13 in Squares 1-2, Layer 5 in Squares 3-4 and Layers 11-16 in Square 55 are yellowish-brown silt loams that contain sporadic faunal bones, mostly Cervidae. The sediment is impregnated with calcium carbonate and might have come from different sources, including decomposing limestone (as indicated by the limestone bioclasts), volcanic sediments (as indicated by the presences of volcanic minerals and rock fragments), and authigenic (generated in situ) carbonates. Some of the faunal remains again show polishing, rounding and abrasion (Piper and Mijares 2007), which could mean that the sediment has undergone some reworking and secondary deposition.

Layer 8 in Square 1-2 was also identified in Square 55 as Layer 10, but was not observed in Square 3-4. Instead, Square 3-4 has a 26,000 BP human occupation layer with a distinctly reddish-brown colour. In situ hearth deposits were observed in Square 3-4, and disturbed deposits apparently related to burning were identified in thin section. This deposit also produced a considerable number of lithic artefacts (Mijares 2007). The absence of this deposit in Squares 3-4 might be due to post-depositional erosion of deposits close to the cave entrance or the occupants of the cave did not utilise this area quite so intensively.

Layers 6 and 7 in Square 1-2, Layer 4 in Square 3-4, and Layers 7 and 8 in Square 55 represent a $10-50 \mathrm{~cm}$ thick volcanic ash layer observed across the antechamber. No archaeological remains were recovered from these layers and the actual volcanic source still needs to be identified. Geochemical analysis of the ash might help with provenance.

Above the volcanic ash was a thick, dark layer rich in biological remains (Layer 5 in Squares 1-2 and Layer 3 in Square 55) but with an absence of archaeological materials. This was not observed in Squares 3-4, which lie closer to the mouth of the antechamber. Phytolith and micromorphological analyses show that some of the biological remains were burnt. It is currently unclear whether these deposits represent a natural burning event or resulted from anthropogenic activity. If people were involved, then the absence of cultural remains would suggest that their main activities were beyond the cave entrance.

Layers 3 and 4 in Squares 1-2, Layer 2 in Squares 3-4, and Layers 1 and 2 in Square 55 represent the $c a .3600-3500$ BP Neolithic activity within the cave entrance. The deposit is composed of a sandy silt loam and soil micromorphological analysis shows that the layer has been highly bioturbated by faunal activity, with a crumb structure. There is also some evidence of burning from the reddened sediment and a high charcoal content with pottery and other material culture. The presence of numerous fragmented human bones and teeth indicates that the antechamber was also utilised for burial during this period.

\section{Conclusions}

Cave sites have complicated depositional and post-depositional histories and require a detailed approach to understanding formation processes. The case of Callao Cave clearly shows the importance of conducting a fine-grained analysis of soil and sediment to determine the processes involved in sediment deposition. Callao Cave, with its important archaeological findings, has greatly benefited from a multidisciplinary approach anchored by contextual information from soil micromorphological analysis. 
At Callao, the depositional history of the antechamber reveals multiple sources of sediment accumulation, from the lower material deposited under phreatic conditions, through a period of reworking and mixing with in-washed sediments, and then a deposition of volcanic ash and authigenic carbonate formation. Other processes observed include bioturbation by soil fauna, cementation with micrite and sparite crystals, oxidation, coating of peds and infilling of voids.

A number of anthropogenic features within at least three phases of human activity were also identified. This included evidence of burning, charcoal, as well as bones and artefacts. The earliest phase of activity occurred between 67,000-54,000 BP and resulted in the deposition of faunal and human bone. The re-deposition of bone fragments towards the interior of the cave suggests that most (if not all) of the activity occurred close to or within the entrance of the cave. Movement of bone appears to have been facilitated by their deposition within a shallow flowchannel that drained from the entrance of the cave into the antechamber close to the east wall. The second phase of habitation occurred during the Late Pleistocene around 28,980-27,420 cal. BP and is evidenced through the identification of an in situ hearth and a lithic scatter close to the east wall of the antechamber. The local presence of people was also inferred in Layer 5, through the identification of high concentrations of burnt plant remains. This was succeeded by cave occupation and burial following the introduction of pottery and other material culture associated with the arrival of Austronesian-speaking peoples in northern Luzon dating to about 3693-3527 cal. BP at Callao. Each phase of human activity was preceded and succeeded by long hiatuses in human activity that suggest only intermittent and sporadic visitations to Callao Cave across many millennia.

\section{Acknowledgements}

I am grateful for the support of the National Museum of the Philippines, the Cagayan Provincial Government, and the Peñablanca Protected Area Management Board. Funding for this research came from an Australian Research Council Discovery Grant to Peter Bellwood and a University of the Philippines Research Grant to Armand Mijares. Funding for processing of the thin sections was partially provided by a New Initiative Grant from the Centre for Archaeological Research at The Australian National University.

\section{References}

Adams, A.E. and W.S. Mackenzie. 2001. A Colour Atlas of Carbonate Sediments and Rocks Under the Microscope. Manson London: Publishing.

Adams, A.E., W.S. Mackenzie and C. Guilford. 1984. Atlas of Sedimentary Rocks under the Microscope. Harlow: Prentice Hall.

Anderson, D. 1997. Cave archaeology in Southeast Asia. Geoarchaeology 12: 607-638. doi.org/10.1002/ (SICI) 1520-6548(199709)12:6<607::AID-GEA5>3.0.CO;2-2.

Aoyagi, Y., M. Aguilera, H. Ogawa and K. Tanaka. 1993. Excavation of Hill Top Site, Magapit Shell Midden in Lal-lo Shell Middens, Northern Luzon, Philippines. Man and Culture in Oceania 9: $127-155$.

Bronk Ramsey, C., M. Dee, S. Lee, T. Nakagawa and R. Staff. 2010. Developments in the calibration and modelling of radiocarbon dates Radiocarbon 52(3): 953-961. doi.org/10.1017/ S0033822200046063. 
Bullock, P., N. Fedoroff, A. Jongerius, G. Stoops and T. Tursina. 1985. Handbook for Soil Thin Section Description. England: Waine Research Publication.

Courty, M.A., P. Goldberg and R. Macphail. 1989. Soils and Micromorphology in Archaeology. Cambridge: Cambridge University Press.

Cuevas, M. 1980. Preliminary Report on the Archaeological Excavation conducted at Callao Caves. Manila: Manuscript of the National Museum.

- 1982. Progress Report on the Archaeological Activities conducted at Callao Caves (November 1980-August 1982). Manila: Manuscript of the National Museum.

Fitzpatrick, E.A. 1984. Micromorphology of Soils. London: Chapman and Hall Ltd. doi.org/10.1007/97894-009-5544-8.

Heaney, L., P. Piper and A.S.B. Mijares. 2011. The first fossil record of endemic murid rodents from the Philippines: a late Pleistocene cave fauna from northern Luzon, Philippines. Proceedings of the Biological Society of Washington 124(3): 234-247. doi.org/10.2988/10-32.1.

Lewis, H. 2003. The potential of soil micromorphology in Southeast Asian archaeology: Preliminary work at Niah Cave Sarawak, Malaysia, and Ille Cave, Palawan, Philippines. Hukay 5: 60-72.

- 2004. The soil micromorphological potential of cultural sediments from cave sites in Island Southeast Asia: progress report on work at Niah, Ille and Tabon Caves. Unpublished report for the Evans Fund, the Society of Southeast Asian Studies, and the Niah Cave Project (AHRB).

- 2007. Preliminary soil micromorphology studies of landscape and occupation history at Tabon Cave, Palawan, Philippines. Geoarchaeology 22: 685-708. doi.org/10.1002/gea.20182.

Mackenzie, W.S. and A.E. Adams. 1994. A Colour Atlas of Rocks and Minerals in Thin Section. London: Manson Publishing.

Magee, J. 1988. Oriented soil samples from Tingkayu Basin. In P. Bellwood (ed.), Archaeological Research in South-eastern Sabah. pp. 31-37. Sabah: Sabah Museum Monograph 2.

Mijares, A. 2001. An expedient lithic technology in Northern Luzon Philippines. Lithic Technology 26(2): 138-152. doi.org/10.1080/01977261.2001.11720983.

- 2005a. The archaeological excavation of Eme, Callao and Dalan Serkot Caves, Northern Luzon, Philippines. Journal of Austronesian Studies 1: 65-93.

—. 2005b. The Nagsabaran Shell Midden Site: A soil micromorphology approach. Hukay 8: 1-12.

- 2007. Unearthing Prehistory: The Archaeology of Northeastern Luzon, Philippine Islands. BAR International Series 1613. Oxford: John and Erica Hedges Ltd.

Mijares, A. and H. Lewis. 2009. Cave sites in Northeastern Luzon, Philippines: A preliminary soil micromorphology study. Asian Perspectives 48: 98-118. doi.org/10.1353/asi.0.0010.

Mijares, A., F. Détroit, P. Piper, R. Grün, P. Bellwood, M. Aubert, G. Champion, N. Cuevas, A. De Leon and E. Dizon. 2010. New evidence for a 67,000-year-old human presence at Callao Cave, Luzon, Philippines. Journal of Human Evolution 59: 123-132. doi.org/10.1016/j.jhevol.2010.04.008.

Morwood, M. and P. van Osterzee. 2007. The Discovery of the Hobbit. Sydney: Random House Australia.

Piper, P. and A. Mijares. 2007. A Preliminary Report on a Late Pleistocene Animal Bone Assemblage from Callao Cave, Penablanca, Northern Luzon, Philippines. Archaeological Studies Program, Quezon City: University of the Philippines. 
Stephens, M., J. Rose, D. Gilbertson and M. Canti. 2005. Micromorphology of cave sediments in the humid tropics: Niah Cave Sarawak. Asian Perspectives 44: 42-55. doi.org/10.1353/ asi.2005.0014.

Stoops, G. 2003. Guidelines for the Analysis and Description of Soil and Regolith Thin Section. Wisconsin: Soil Science Society of America, Inc.

Zauyah, S. 1994. Characteristic of Soil Layers in Gua Gunung Runtuh. In M. Zuraina (ed.),

The Excavation of Gua Gunung Runtuh and the Discovery of the Perak Main in Malaysia, pp. 123-140. Kuala Lampur: Department of Museums and Antiquity Malaysia. 
This text is taken from New Perspectives in Southeast Asian and Pacific Prehistory, edited by Philip J. Piper, Hirofumi Matsumura and David Bulbeck, published 2017 by ANU Press, The Australian National University, Canberra, Australia. 